\title{
An exploration study to find important factors influencing on enterprise resource planning
}

\author{
Naser Azad*, Atieh Shadmanfard and Seyed Foad Zarifi
}

Department of Management, Islamic Azad University, South Tehran Branch, Tehran, Iran

CHRONICLE ABSTRACT

Article history:

Received May 12, 2013

Received in revised format

12 August 2013

Accepted 18 August 2013

Available online

August 192013

Keywords:

Enterprise resource planning

Factor analysis

Iran Khodro

\begin{abstract}
Enterprise resource planning (ERP) has become a necessary in many organizations and many business units have been trying to emerge into an integrated system. There are many advantages on having an efficient ERP but many corporations fail to reach a full operational ERP for many reasons. In this paper, we present an empirical investigation to find important factors influencing ERP implementation in one of the biggest Iranian automakers named Iran Khodro. The proposed study designs a questionnaire in Likert scale consists of 46 questions, distributes it among some managers in this firm. Cronbach alpha is calculated as 0.802. In addition, KaiserMeyer-Olkin Measure of Sampling Adequacy and Approx. Chi-Square are 0.788 and 1677.307, respectively. Based on the results of our survey, we have derived eight factors including intelligence information, customer comfort, structure oriented, resource management, process oriented, customer oriented, flexible structure and knowledge management.
\end{abstract}

\section{Introduction}

During the past few decades, there have been tremendous changes on many corporations and business units (Shtub \& Karni, 2009). Many of them have relocated their production units in various countries in an attempt to reduce their expenses such as transportation, accessing to cheaper human resources, etc. In such circumstances, it is necessary to have an updated and integrated system to meet necessary requirements as quickly as possible. For instance, when a customer in United States places an online order from an automaker, there must be an immediate message in ordering in production unit, inventory management, etc. to make sure that the order meets its necessary parts and particle. In other words, in production of a vehicle, over a million parts are required where most of them are prepared from various places and only an integrated system could properly handle this. Enterprise resource 
planning (ERP) plays an essential role on the success of on time delivery of products; it reduces duplicated information and provides a uniform flow of the information through a corporation. Despite the fact that there are many advantages on having ERP systems, many ERP systems fail to implement it, properly. In fact, there are different reports, which indicate that many ERP systems reach undesirable results in United States. Therefore, it is necessary to perform an exploration study to find out more about the factors influencing ERP implementation.

Candra (2012) determined the key antecedents to successful ERP implementation based on knowledge capability perspectives and it helped to understand the key success factor in enterprise resource planning implementation. The survey implies that knowledge capability influences the success of ERP implementation. Ross (1999) examined the implications for its information systems' requirements, decided to acquire an integrated, enterprise-wide software package named SAP and embarked on its implementation. Bradley (2008) investigated critical success factors for ERP implementation using the framework of classical management theory. The study was motivated by conflicting results in earlier studies investigating critical success factors in ERP implementation, many of which are anecdotal in nature. The study selected ten critical success factors in ERP systems implementation and examined the relationship between each of these factors and project success. Project success was defined as organizational impact and on time and on/under budget project completion. The study concentrated on eight implementation projects qualitatively using the case study method to verify the proposed relationships. The findings suggested choosing the right full time project manager, training of personnel, and the presence of a champion relate to project success. The implementation of consultants, the role of management in reducing user resistance and applying a steering committee to control the project did not seem to differentiate successful and unsuccessful projects. Integration of ERP planning with business planning, reporting level of the project manager, and active participation of the CEO beyond project approvals, resource allocation and occasional project review, were not also found to be critical factors of success. Considering the financial cost and risk associated with these projects, a better understanding of critical success factors definitely helps practitioners and academics to improve the chance of success in the implementation projects.

Boltena and Gomez (2012) presented a case study of an ERP system implementation by a medium company in Ethiopia. The study investigated key dimensions of implementation of ERP system within MIE and looked an in-depth at the issues behind the process of ERP implementation by concentrating on business and technical as well as cultural issues at the heart of the MIE implementation. The case study also looked at applying risks and reports how MIE coped with the typical challenges that most medium organizations faced when applying an ERP system. Berchet and Habchi (2005) studied the integration and deployment of the ERP project at Alcatel, a telecommunications company. They presented a detailed framework of the planning process and implemented as a tool to facilitate the firm's key users at various stages of the planning process. In order to improve the control process of the planning system, they developed a control helping system based on performance indicators, and particularly dedicated to control the material requirement planning activities. The objective of this project was to improve the reactivity of the planning system as well as to enhance that of the supply chain. Powell et al. (2013) suggested that modern developments in information technology (IT) and the onset of hybrid "push-pull" production control mechanisms have allowed ERP and lean approaches to converge towards a state where ERP systems is applied to support the deployment of lean practices. They also analysed typical lean and ERP implementation processes contained within the scientific literature, and by further investigating a concurrent implementation process in real-time, they developed and propose a process for ERP-based lean implementations. The findings implied that the implementation of a contemporary ERP system could act as a catalyst for the application of lean production practices. Morton and $\mathrm{Hu}$ (2008) implemented the structural contingency theory to determine a set of dimensions of organizational structure and ERP system characteristics that can be implemented to gauge the degree of fit, thus providing some insights into successful ERP implementations. 
Ifinedo et al. (2010) investigated the relationships among six constructs or dimensions in ERP system success measurement model developed from prior relevant frameworks. They also contributed to the body of knowledge in the information system (IS) success evaluation domain, especially with its focus on ERP packages. They used structural equation modeling (SEM) to examine six relevant hypotheses and reported that five out of the six hypotheses had significant, positive associations including the constructs of System Quality, Service Quality, Individual Impact, Workgroup Impact, and Organizational Impact. Ke and Wei (2008) theorized how leadership influences ERP implementation by fostering the desired organizational culture. They contend that ERP implementation success was positively associated with organizational culture along the dimensions of learning and development, participative decision making, power sharing, support and collaboration, and tolerance for risk and conflicts. Besides, they identified the strategic and tactical actions that the top management could take to impact organizational culture and foster a culture conducive to ERP implementation.

\section{The proposed study}

This paper presents an empirical investigation to find important factors influencing implementation of ERP systems. The proposed study designs a questionnaire in Likert scale consists of 45 questions, distributes it among some experts. Cronbach alpha is calculated as 0.802. In addition, Kaiser-MeyerOlkin Measure of Sampling Adequacy and Approx. Chi-Square are 0.788 and 1677.307, respectively. Since we plan to factor analysis and this method is sensitive to skewness of the data we first look at some of the basic statistics including the skewness of the data and decided to reduce the number of questions to 31 questions. The study uses principal component analysis and Table 1 demonstrates the summary of our findings on communalities.

\section{Table 1}

The summary of communalities

\begin{tabular}{|c|c|c|c|}
\hline Variable & Description & Initial & Extraction \\
\hline 1 & Organizational flexibility & 1.000 & .482 \\
\hline 2 & Project management & 1.000 & .445 \\
\hline 3 & Dynamic communication among managers & 1.000 & .522 \\
\hline 4 & Security of information system & 1.000 & .445 \\
\hline 5 & Training employees & 1.000 & .475 \\
\hline 6 & Standard process & 1.000 & .459 \\
\hline 7 & Organizational culture & 1.000 & .513 \\
\hline 8 & Leadership & 1.000 & 616 \\
\hline 9 & Supply chain management & 1.000 & .520 \\
\hline 10 & Communication channels & 1.000 & .534 \\
\hline 11 & Operating costs & 1.000 & .473 \\
\hline 12 & Time management & 1.000 & .489 \\
\hline 13 & Economic management & 1.000 & .481 \\
\hline 14 & Effective customer relationship management & 1.000 & .479 \\
\hline 15 & MIS & 1.000 & .546 \\
\hline 16 & Database & 1.000 & .612 \\
\hline 17 & Updated data & 1.000 & .447 \\
\hline 18 & Strategic information technology & 1.000 & .477 \\
\hline 19 & Information technology & 1.000 & .451 \\
\hline 20 & Integrated operations & 1.000 & .642 \\
\hline 21 & Process control & 1.000 & .619 \\
\hline 22 & Automated process & 1.000 & .489 \\
\hline 23 & Product development & 1.000 & .608 \\
\hline 24 & Customer relationship management & 1.000 & .676 \\
\hline 25 & Delivering services to customers & 1.000 & .524 \\
\hline 26 & Organizational changes & 1.000 & .488 \\
\hline 27 & Organizational mergers & 1.000 & .556 \\
\hline 28 & Re-engineering & 1.000 & .493 \\
\hline 29 & Organizational objectives & 1.000 & .517 \\
\hline 30 & Commitment agenda & 1.000 & .485 \\
\hline 31 & Quality of information & 1.000 & .653 \\
\hline
\end{tabular}


Table 2 demonstrates the results of factor analysis on these factors.

Table 2

The summary of principal component analysis after rotation

\begin{tabular}{|c|c|c|c|c|c|c|}
\hline \multirow[b]{2}{*}{ Component } & \multicolumn{3}{|c|}{ Initial Eigenvalues } & \multicolumn{3}{|c|}{ Extraction Sums of Squared Loadings } \\
\hline & Total & $\%$ of Variance & Cumulative \% & Total & \% of Variance & Cumulative \% \\
\hline 1 & 4.987 & 16.088 & 16.088 & 4.987 & 16.088 & 16.088 \\
\hline 2 & 2.130 & 6.870 & 22.957 & 2.130 & 6.870 & 22.957 \\
\hline 3 & 1.770 & 5.708 & 28.666 & 1.770 & 5.708 & 28.666 \\
\hline 4 & 1.566 & 5.053 & 33.719 & 1.566 & 5.053 & 33.719 \\
\hline 5 & 1.275 & 4.113 & 37.832 & 1.275 & 4.113 & 37.832 \\
\hline 6 & 1.190 & 3.839 & 41.671 & 1.190 & 3.839 & 41.671 \\
\hline 7 & 1.136 & 3.665 & 45.336 & 1.136 & 3.665 & 45.336 \\
\hline 8 & 1.110 & 3.580 & 48.915 & 1.110 & 3.580 & 48.915 \\
\hline 9 & 1.055 & 3.402 & 52.318 & 1.055 & 3.402 & 52.318 \\
\hline 10 & .984 & 3.175 & 55.492 & & & \\
\hline 11 & .965 & 3.112 & 58.605 & & & \\
\hline 12 & .945 & 3.050 & 61.654 & & & \\
\hline 13 & .912 & 2.943 & 64.598 & & & \\
\hline 14 & .901 & 2.906 & 67.504 & & & \\
\hline 15 & .847 & 2.733 & 70.236 & & & \\
\hline 16 & .809 & 2.611 & 72.847 & & & \\
\hline 17 & .766 & 2.472 & 75.319 & & & \\
\hline 18 & .749 & 2.416 & 77.735 & & & \\
\hline 19 & .728 & 2.347 & 80.082 & & & \\
\hline 20 & .661 & 2.133 & 82.216 & & & \\
\hline 21 & .631 & 2.035 & 84.251 & & & \\
\hline 22 & .601 & 1.937 & 86.188 & & & \\
\hline 23 & .563 & 1.817 & 88.004 & & & \\
\hline 24 & .548 & 1.769 & 89.773 & & & \\
\hline 25 & .533 & 1.718 & 91.491 & & & \\
\hline 26 & .529 & 1.706 & 93.197 & & & \\
\hline 27 & .474 & 1.528 & 94.725 & & & \\
\hline 28 & .451 & 1.454 & 96.179 & & & \\
\hline 29 & .418 & 1.347 & 97.526 & & & \\
\hline 30 & .393 & 1.266 & 98.792 & & & \\
\hline 31 & .374 & 1.208 & 100.000 & & & \\
\hline
\end{tabular}

Beside the results of Table 2, we have looked at Scree plot to determine important factors and the results of figure and Table indicate that there were eight factors.

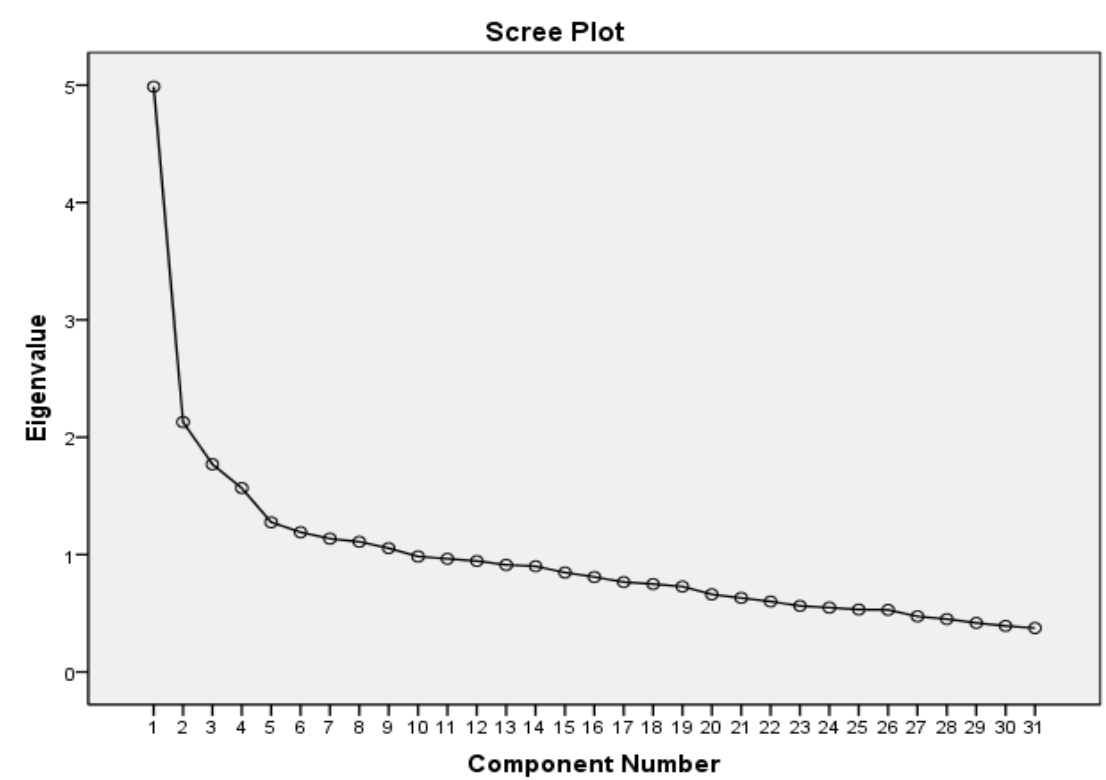

Fig. 1. The results of Scree plot

Based on the results of our survey, we have derived eight factors including intelligence information, customer comfort, structure oriented, resource management, process oriented, customer oriented, flexible structure and knowledge management summarized in Table 3 as follows, 
Table 3

The summary of factor analysis

\begin{tabular}{|c|c|c|c|c|c|}
\hline Factor & Measurable variable & Weight & $\begin{array}{c}\text { Eigenvalue } \\
\text { Eigen }\end{array}$ & Variance & Accumulated \\
\hline \multirow{5}{*}{$\begin{array}{l}\text { Intelligence } \\
\text { information }\end{array}$} & Database & 0.727 & 4.987 & 16.088 & 16.088 \\
\hline & MIS & 0.691 & & & \\
\hline & Information technology & 0.498 & & & \\
\hline & Strategic IT planning & 0.569 & & & \\
\hline & Updated information & 0.533 & & & \\
\hline \multirow{4}{*}{$\begin{array}{l}\text { customer } \\
\text { comfort }\end{array}$} & Customer relationship management & 0.792 & 2.130 & 22.957 & 22.957 \\
\hline & Schedule to meet commitments & 0.625 & & & \\
\hline & Product development & 0.579 & & & \\
\hline & Delivering services to customers & 0.512 & & & \\
\hline \multirow{4}{*}{ structure oriented } & Organizational objectives & 0.656 & 1.770 & 28.666 & 28.666 \\
\hline & Re-engineering & 0.615 & & & \\
\hline & Organizational change & 0.560 & & & \\
\hline & Organizational merges & 0.353 & & & \\
\hline \multirow{3}{*}{$\begin{array}{l}\text { Resource } \\
\text { management }\end{array}$} & Time management & 0.628 & 1.566 & 33.719 & 33.719 \\
\hline & Operational expenses & 0.605 & & & \\
\hline & Economic management & 0.361 & & & \\
\hline \multirow[t]{3}{*}{ Process oriented } & Integrated operating planning & 0.492 & 1.275 & 37.832 & 37.832 \\
\hline & Process control & 0.772 & & & \\
\hline & Automated processes & 0.640 & & & \\
\hline \multirow{3}{*}{$\begin{array}{l}\text { Customer } \\
\text { oriented }\end{array}$} & Effective customer relationships & 0.394 & 1.190 & 41.671 & 41.671 \\
\hline & Communication channels & 0.685 & & & \\
\hline & Supply chain management & 0.589 & & & \\
\hline \multirow{4}{*}{ Flexible structure } & Organizational flexibility & 0.656 & 1.190 & 41.671 & 41.671 \\
\hline & Project management & 0.619 & & & \\
\hline & Organizational culture & 0.424 & & & \\
\hline & Leadership & 0.460 & & & \\
\hline \multirow{4}{*}{$\begin{array}{l}\text { Knowledge } \\
\text { management }\end{array}$} & Dynamic management communication & 0.634 & 1.110 & 48.915 & 48.915 \\
\hline & Employee training & 0.572 & & & \\
\hline & Secure information systems & 0.533 & & & \\
\hline & Standard processes & 0.343 & & & \\
\hline
\end{tabular}

\section{Discussion and conclusion}

The results of Table 3 indicate that there were eight factors including intelligence information, customer comfort, structure oriented, resource management, process oriented, customer oriented, flexible structure and knowledge management influencing ERP implementation.

Intelligence information is the first factor consists of five sub-component including Database, MIS, information technology, strategic IT planning and updated information. The survey, having a reliable and comprehensive database is considered as the most important factor for the success of ERP implementation. Customer comfort is the second most important factor in our survey with four subfactors: Customer relationship management (CRM), schedule to meet commitments, product development and delivering services to customers where CRM is the critical factor.

Structure orientation is the third influential factor on ERP implementation with for items including organizational objectives, re-engineering, organizational change and organizational merges. Resource management is the fourth factor in our survey with three factors including time management, operational expenses and economic management. The fifth factor, process orientation, involves with three items of integrated operating planning, process control and automated processes where integrated operating planning is the most important one. The next factor, customer oriented, consists of effective customer relationships, communication channels and supply chain management. The seventh factor, flexible structure, includes four factors including Organizational flexibility, project 
management, organizational culture and leadership. Finally, knowledge management is the last option with four components including dynamic management communication, employee training, secure information systems and standard processes. The results of our survey are somehow consistent with findings of Candra, S. (2012) and Ifinedo et al. (2010).

\section{Acknowledgment}

The authors would like to thank the anonymous referees for their construction comments on earlier version of this work.

\section{References}

Berchet, C., \& Habchi, G. (2005). The implementation and deployment of an ERP system: An industrial case study. Computers in Industry, 56(6), 588-605.

Boltena, A. S., \& Gomez, J. M. (2012). A successful ERP implementation in an Ethiopian company: A case study of ERP implementation in Mesfine industrial engineering Pvt. Ltd. Procedia Technology, 5, 40-49.

Bradley, J. (2008). Management based critical success factors in the implementation of enterprise resource planning systems. International Journal of Accounting Information Systems, 9(3), 175200.

Candra, S. (2012). ERP implementation success and knowledge capability. Procedia-Social and Behavioral Sciences, 65, 141-149.

Ifinedo, P., Rapp, B., Ifinedo, A., \& Sundberg, K. (2010). Relationships among ERP postimplementation success constructs: An analysis at the organizational level. Computers in Human Behavior, 26(5), 1136-1148.

Ke, W., \& Wei, K. K. (2008). Organizational culture and leadership in ERP implementation. Decision Support Systems, 45(2), 208-218.

Morton, N. A., \& Hu, Q. (2008). Implications of the fit between organizational structure and ERP: A structural contingency theory perspective. International Journal of Information Management, 28(5), 391-402.

Powell, D., Alfnes, E., Strandhagen, J. O., \& Dreyer, H. (2013). The concurrent application of lean production and ERP: Towards an ERP-based lean implementation process. Computers in Industry, 64(3), 324-335.

Ross, J. (1999). Dow Corning Corporation: business processes and information technology. Journal of Information Technology, 14(3), 253-266.

Shtub, A., \& Karni, R. (2009). ERP: the dynamics of supply chain and process management. Springer. 